\title{
High-Frequency Chest-Wall Oscillation in a Noninvasive-Ventilation-Dependent Patient With Type 1 Spinal Muscular Atrophy
}

\author{
Joanna M Keating, Nicola Collins, Andrew Bush MD PhD, and Michelle Chatwin PhD
}

\begin{abstract}
With the recent increased use of noninvasive ventilation, the prognoses of children with neuromuscular disease has improved significantly. However, children with muscle weakness remain at risk for recurrent respiratory infection and atelectasis. We report the case of a young girl with type 1 spinal muscular atrophy who was dependent on noninvasive ventilation, and in whom conventional secretion-clearance physiotherapy became insufficient to clear secretions. We initiated high-frequency chest-wall oscillation (HFCWO) as a rescue therapy, and she had improved self-ventilation time. This is the first case report of HFCWO for secretion clearance in a severely weak child with type 1 spinal muscular atrophy. In a patient with neuromuscular disease and severe respiratory infection and compromise, HFCWO can be used safely in combination with conventional secretionclearance physiotherapy. Key words: noninvasive ventilation; NIV; neuromuscular disease; pediatric; respiratory infection; atelectasis; spinal muscular atrophy; high-frequency chest-wall oscillation; HFCWO; secretion clearance; cough; insufflation/exsufflation; intrapulmonary percussive ventilation. [Respir Care 2011;56(11):1840-1843. () 2011 Daedalus Enterprises]
\end{abstract}

\section{Introduction}

A major cause of morbidity and mortality in patients with type 1 spinal muscular atrophy is early respiratory failure. Noninvasive ventilation (NIV) reduces hospitalizations, intensive-care admissions ${ }^{1}$ and corrects sleep-disordered breathing, ${ }^{2}$ thus improving the prognosis of children with neuromuscular disease. ${ }^{3}$ However, children with respiratory-muscle weakness are still at risk for recurrent lower-respiratory-tract infections and atelectasis because

Ms Keating and Ms Collins are affiliated with the Department of Physiotherapy; Professor Bush is affiliated with the Department of Paediatrics; and Dr Chatwin is affiliated with the Academic and Clinical Department of Sleep and Breathing, Royal Brompton Hospital, London, United Kingdom.

Dr Chatwin was partly supported by a grant from the Jennifer Trust for Spinal Muscular Atrophy, United Kingdom, and has disclosed a relationship with Breas Medical. The other authors have disclosed no conflicts of interest.

Correspondence: Michelle Chatwin, Academic and Clinical Department of Sleep and Breathing, Royal Brompton Hospital, Sydney Street, London SW3 6NP United Kingdom. E-mail m.chatwin@rbht.nhs.uk.

DOI: $10.4187 /$ respcare. 01155 of impaired cough and poor airway clearance. Ineffective airway clearance can be exacerbated by acute respiratory illnesses when secretion production increases and respiratory-muscle function can acutely deteriorate. ${ }^{4}$

We previously reported our use of NIV and mechanical insufflation/exsufflation in patients with type 1 spinal muscular atrophy. ${ }^{5}$ In the present report we highlight another rescue therapy for a child with spinal muscular atrophy who is NIV-dependent and whose normal airway-clearance regimen became insufficient.

We report on a child who had type 1 spinal muscular atrophy with ongoing mucus plugging despite intensive physiotherapy and mechanical insufflation/exsufflation, and our experience with the novel addition of high-frequency chest-wall oscillation (HFCWO) with the RTX (Medivent International, London, United Kingdom) negative-pressure noninvasive ventilator. The pressure is transmitted externally via a cuirass, a shell-like plastic jacket that forms an air-tight seal around the patient's trunk (Fig. 1). It can ventilate in controlled or synchronized modes and has a secretion-clearance function that incorporates both vibration and cough modes. The cough mode involves a long high-pressure inspiratory phase followed by a short expiratory phase. The cough mode interrupts the vibration mode (external HFCWO) at a frequency set by the therapist. 


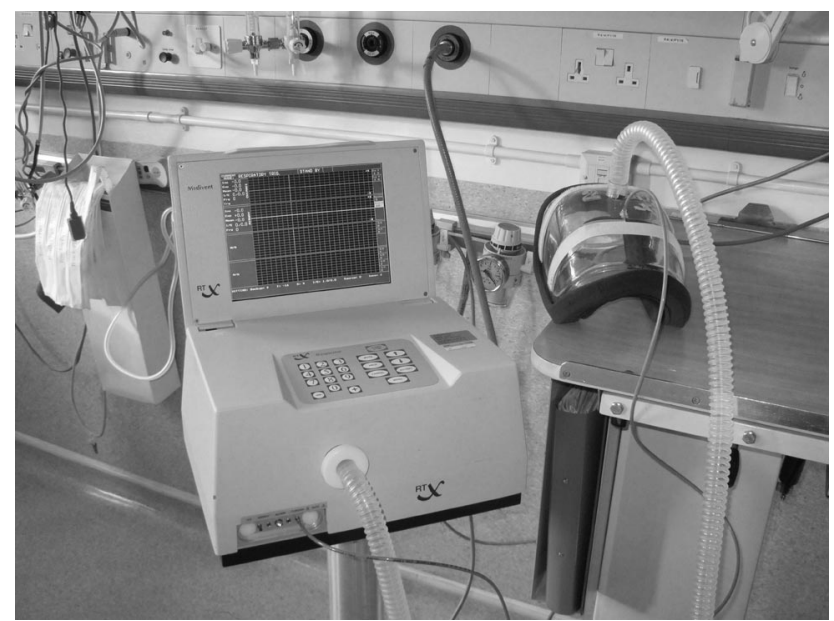

Fig. 1. The RTX negative-pressure noninvasive ventilator. The pressures are transmitted externally, via the cuirass (right).

\section{Case Report}

The patient was a 21-month-old female with genetically confirmed type 1 spinal muscular atrophy. At 8 months of age she had poor head control and reduced antigravity movements in all limbs. At the time she presented she had no respiratory symptoms. Her first admission to our center was as an emergency transfer, at 12 months of age. She was intubated and mechanically ventilated due to a lowerrespiratory-tract infection and following therapy she was successfully extubated to NIV. After extubation she received intensive physiotherapy (increased ventilation pressures, manual percussion, and mechanical insufflation/exsufflation). During this admission, videofluoroscopy revealed an unsafe swallow and esophageal $\mathrm{pH}$ testing showed severe gastroesophageal reflux. Subsequently she underwent Nissen fundoplication and gastrostomy. Glycopyrronium bromide was also started for excessive oral secretions. Following a long recovery period she was discharged with NIV for nocturnal use, set at an inspiratory pressure of $16 \mathrm{~cm} \mathrm{H}_{2} \mathrm{O}$ and an expiratory pressure of $6 \mathrm{~cm} \mathrm{H}_{2} \mathrm{O}$. Her parents were trained in physiotherapy techniques and provided with a mechanical insufflation/exsufflation device (CoughAssist, Philips-Respironics, Murrysville, Pennsylvania) for home use.

She had 4 hospital admissions within the next year and during one admission, negative-pressure ventilation was commenced to avoid nasal-bridge sores from continuous oronasal-mask NIV. On each admission she became increasingly dependent on NIV during the acute phase. Because of her young age she was unable to perform spirometry or the peak-cough-flow maneuver.

At 21 months of age she was admitted to her local hospital with increased sputum volume and increased work of breathing. She was NIV-dependent and her ventilation
Table 1. Set Variables on the RTX Noninvasive Negative-Pressure Ventilator

\begin{tabular}{lcccc}
\hline \hline Frequency & $\begin{array}{c}\text { Inspiratory } \\
\text { Pressure } \\
\left(\mathrm{cm} \mathrm{H}_{2} \mathrm{O}\right)\end{array}$ & $\begin{array}{c}\text { Expiratory } \\
\text { Pressure } \\
\left(\mathrm{cm} \mathrm{H}_{2} \mathrm{O}\right)\end{array}$ & $\begin{array}{c}\text { Inspiratory/ } \\
\text { Expiratory } \\
\text { Ratio }\end{array}$ \\
\hline Vibration mode & 360 cycles/min & 15 & 15 & $1: 1$ \\
Cough mode & 10 coughs/min & 15 & 25 & $2: 1$ \\
\hline
\end{tabular}

settings were increased to an inspiratory pressure of $18 \mathrm{~cm} \mathrm{H}_{2} \mathrm{O}$ and an expiratory pressure of $8 \mathrm{~cm} \mathrm{H}_{2} \mathrm{O}$. She also required supplemental oxygen at $4 \mathrm{~L} / \mathrm{min}$ and tested positive for nasopharyngeal adenovirus. After 6 weeks she was transferred to our center, at which time sputum microbiology and virology were negative. Blood tests showed a C-reactive protein of $24 \mathrm{mg} / \mathrm{L}(0-10 \mathrm{mg} / \mathrm{L})$ and a whitecell count of $6.8 \times 10^{9}$ cells $/ \mathrm{L}$ (range $6.0-17.5 \times 10^{9}$ cells). Sputum volume remained elevated. Glycopyrronium bromide was withheld at this time due to mucus plugging. She was receiving continuous gastrostomy feeding and ventilation requirements were unchanged from the alterations made at the local hospital. Admission chest radiograph showed right-lower-lobe collapse with a dense opacification and air bronchograms. There were also linear opacifications within the right upper zone and the left lower lobe in keeping with atelectasis.

Airway clearance (increased ventilation pressure, manual percussion, and mechanical insufflation/exsufflation) was performed 4 times a day including at night. This was supplemented with additional nasopharyngeal or oral suctioning if $\mathrm{S}_{\mathrm{PO}_{2}}$ fell below 95\%. During physiotherapy she frequently desaturated. Additional supplemental oxygen was given but the desaturations were probably due to excessive secretions since they resolved with further airway clearance. After a week blood-test results continued to improve, C-reactive protein was $18 \mathrm{mg} / \mathrm{L}$ and sputum virology and microbiology remained negative. However, atelectasis persisted on chest radiograph, desaturations continued during physiotherapy and attempts to wean her from NIV caused her to become clammy, tachycardic and desaturated. As there was no improvement, the physiotherapy regimen required further optimization. In discussion with the team and with consent from the parents, HFCWO with the RTX was introduced as a form of airway clearance (Table 1) and used in combination with NIV prior to standard physiotherapy sessions. The HFCWO was well tolerated. She had no desaturations during HFCWO or in the post-HFCWO conventional physiotherapy. However, no further physiological measurements were made as invasive monitoring was deemed inappropriate because it would cause undue distress. Although, not objectively measured because of her young age, she appeared to clear a larger volume of secretions following the HFCWO sessions and these sessions were consequently shorter than 


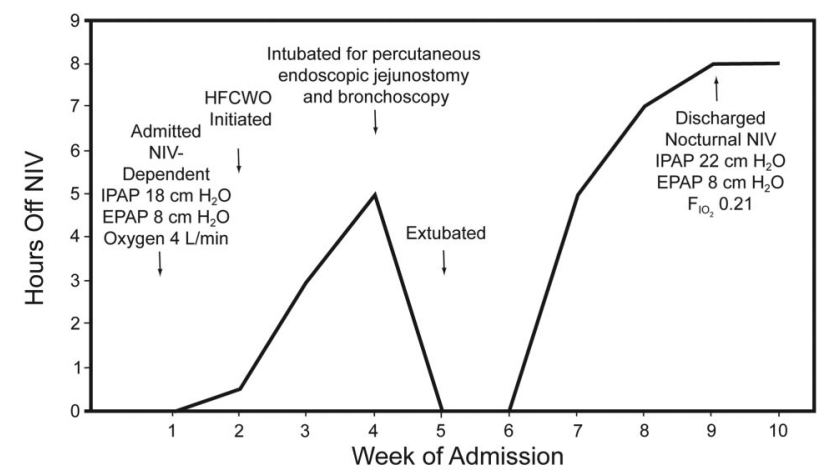

Fig. 2. Daily hours off of noninvasive ventilation (NIV) in our patient's clinical course. IPAP = inspiratory positive airway pressure. EPAP = expiratory positive airway pressure. HFCWO = high-frequency chest-wall oscillation.

the sessions that involved only conventional physiotherapy. We continued with 4 HFCWO sessions each day for the next 2 weeks. Attempts to wean NIV continued this time successfully. Fourteen days after initiating HFCWO she achieved 5 hours of self-ventilation time (Fig. 2). However, she had begun to retch and there was minimal improvement in chest radiograph.

There was concern that the retching was related to gastroesophageal reflux. A pegogram did not show failure of the fundoplication, however, the gastroenterologist felt that with a full stomach she could still be experiencing gastroesophageal reflux, thereby exacerbating secretions. Her gastrostomy was subsequently changed to a percutaneous jejunostomy tube, and bronchoscopy showed some loose secretions, which were easily removed but which made no improvement to the chest radiograph. She was transiently intubated for the procedures and extubated back onto NIV. We continued the HFCWO plus conventional physiotherapy sessions in this period. Five days after extubation we re-commenced self-ventilation trials. The self-ventilation trial periods were cautiously increased by approximately 15 minutes each day and were well tolerated. We increased the self-ventilation periods more quickly and 7 days later she was tolerating 5 continuous hours off of NIV. At this point because the secretions were loose we re-commenced glycopyrronium bromide. Pseudomonas aeruginosa was isolated in suctioned nasopharyngeal sputum, and we administered one mega-unit of nebulized colistin twice daily. Chest radiograph showed resolution of the left-lower-lobe atelectasis. She continued to wean successfully from NIV up to a maximum of 8 hours. On discharge she was using NIV overnight and for sleeping during the day, and was discharged with an inspiratory pressure of $22 \mathrm{~cm} \mathrm{H}_{2} \mathrm{O}$ and an expiratory pressure of $8 \mathrm{~cm} \mathrm{H}_{2} \mathrm{O}$. The team decided not to wean the pressures further, in an attempt to maintain lung recruitment. In a pre-discharge team meeting that included the parents we agreed that the girl would be intubated if necessary in the future to manage acute episodes. At present there are no plans to perform tracheostomy, though this option has been discussed with her parents.

\section{Discussion}

To our knowledge this is the first report of HFCWO in a severely unwell NIV-dependent patient with type 1 spinal muscular atrophy. With advances in medical therapy and, thereby, increased life expectancy of patients with spinal muscular atrophy, it is inevitable that new clinical and ethical challenges will be faced. This case involved a novel application of an established therapy as a safe addition to airway clearance.

Optimizing secretion mobilization is imperative. We suggest that airway-clearance techniques should not be limited to conventional physiotherapy and mechanical insufflation/exsufflation. Mechanical insufflation/exsufflation devices increase cough peak flow ${ }^{6,7}$ and favorable results with mechanical insufflation/exsufflation and NIV alone have been reported. ${ }^{8}$ It is common practice in the United Kingdom to use secretion-mobilization techniques in combination with mechanical insufflation/exsufflation to expel secretions. Furthermore, a United Kingdom study showed that combined secretion-mobilization techniques plus mechanical cough augmentation shorten secretion-clearance sessions in patients with neuromuscular disease. ${ }^{9}$ While mechanical insufflation/exsufflation may be effective in isolation in a stable child, other options must be considered in an exacerbation with excessive secretion production.

This case demonstrates a safe use of the RTX in a patient with type 1 spinal muscular atrophy. Our choice of HFCWO device was based on previous experience with the RTX in other contexts, and proved appropriate for our patient. However, in a patient with severe chest-wall deformity it may be difficult to achieve an adequate seal with the RTX cuirass. If proper sealing or positioning of the RTX cuirass is impossible, other HFCWO devices (eg, the Vest [Hill-Rom, St Paul, Minnesota] or SmartVest [Electromed, New Prague, Minnesota]) could be considered in conjunction with NIV.

A limitation of this case report is that we cannot be certain the child's improvement was solely attributable to the addition of HFCWO. She was not improving despite aggressive physiotherapy and medical management, so it was imperative to optimize her treatment. She had improved self-ventilation time with HFCWO, but she was receiving several therapies, so we cannot be sure that HFCWO was responsible for the change. This report is also predominantly observational and lacks robust physiological data to clearly identify the clinical changes after the addition of HFCWO. In the majority of cases, conven- 


\section{HFOV for an NIV-Dependent Patient With Type 1 Spinal Muscular Atrophy}

tional physiotherapy and mechanical insufflation/exsufflation may be sufficient for the treatment of respiratory deterioration in patients with type 1 spinal muscular atrophy. However, this case highlights HFCWO as a possible physiotherapy adjunct. HFCWO used in isolation from other physiotherapy techniques was safe and was associated with reduced sputum volume and reduced frequency of suctioning in a small cohort of patients with amyotrophic lateral sclerosis, ${ }^{10}$ but further investigation is needed to prove its efficacy.

When a child fails to improve, all potential influencing factors must be considered, and holistic management of a child with neuromuscular disease is essential. Our patient had an unsafe swallow. Bulbar dysfunction is common in patients with spinal muscular atrophy, ${ }^{11}$ which increases the risk of under-nutrition and aspiration. Optimal supplementary feeding is therefore essential, and gastrostomy feeding is an option for children with neuromuscular disease and who are unable to feed adequately by mouth. ${ }^{12}$ However, gastrostomy placement can worsen gastroesophageal reflux, which may exacerbate respiratory symptoms. There is currently uncertainty regarding the optimal treatment of gastroesophageal reflux in children with neuromuscular disease. Our patient underwent a fundoplication; however, high rates of recurrent gastroesophageal reflux after fundoplication have been reported, ${ }^{13}$ and, because we suspected reflux in our patient, we performed percutaneous endoscopic jejunostomy.

This case suggests that HFCWO can be used safely in combination with conventional physiotherapy and mechanical insufflation/exsufflation in patients with type 1 spinal muscular atrophy. In our patient HFCWO was associated with an increase in ventilator-free time. However, the clinical improvements cannot be proven to have been from the HFCWO, so further assessment is warranted to assess the efficacy of HFCWO in patients with type 1 spinal muscular atrophy.

\section{REFERENCES}

1. Katz S, Selvadurai H, Keilty K, Mitchell M, MacLusky I. Outcome of non-invasive positive pressure ventilation in paediatric neuromuscular disease. Arch Dis Child 2004;89(2):121-124.

2. Barbe F, Quera-Salva MA, de Lattre J, Gajdos P, Agusti AG. Longterm effects of nasal intermittent positive-pressure ventilation on pulmonary function and sleep architecture in patients with neuromuscular diseases. Chest 1996;110(5):1179-1183.

3. Bush A, Fraser J, Jardine E, Paton J, Simonds A, Wallis C. Respiratory management of the infant with type 1 spinal muscular atrophy. Arch Dis Child 2005;90(7):709-711.

4. Miske LJ, Hickey EM, Kolb SM, Weiner DJ, Panitch HB. Use of the mechanical in-exsufflator in pediatric patients with neuromuscular disease and impaired cough. Chest 2004;125(4):1406-1412.

5. Chatwin M, Bush A, Simonds AK. Outcome of goal-directed noninvasive ventilation and mechanical insufflation/exsufflation in spinal muscular atrophy type I. Arch Dis Child 2011;96(5):426-432.

6. Bach JR. Mechanical insufflation-exsufflation: a comparison of peak expiratory flows with manually assisted coughing techniques. Chest 1993;104(5):1553-1562.

7. Chatwin M, Ross E, Hart N, Nickol AH, Polkey MI, Simonds AK. Cough augmentation with mechanical insufflation/exsufflation in patients with neuromuscular weakness. Eur Respir J 2003;21(3):502508 .

8. Tzeng AC, Bach JR. Prevention of pulmonary morbidity for patients with neuromuscular disease. Chest 2000;118(5):1390-1396.

9. Chatwin M, Simonds A. The addition of mechanical insufflation/ exsufflation shortens airway-clearance sessions in neuromuscular patients with chest infection. Respir Care 2009;24(11):1473-1479.

10. Lange DJ, Lechtzin N, Davey C, David W, Heiman-Patterson T, Gelinas D, et al. High-frequency chest wall oscillation in ALS: an exploratory randomized, controlled trial. Neurology 2006;67(6):991997.

11. Vernon-Roberts APBS. Fundoplication versus post-operative medication for gastro-oesophageal reflux in children with neurological impairment undergoing gastrostomy. Cochrane Database Syst Rev 2007;(1):CD006151.

12. Ramelli GP, Aloysius A, King C, Davis T, Muntoni F. Gastrostomy placement in paediatric patients with neuromuscular disorders: indications and outcome. Dev Med Child Neurol 2007;49(5):367-371.

13. Boesch RP, James DA. Outcomes of fundoplication in children with cystic fibrosis. J Pediatr Surg 2007;42(8):1341-1344. 